Scientific Journal of October 6 University

ISSN (Print): 2314-8640

ISSN (Electronic): 2356-8119

Published by October 6 University (C) All Rights Reserved

Available online at: http:// sjou.journals.ekb.eg

Original Article
Citation: Magdy et al., (2014). Immunosuppressive Toxic Effects of Ochratoxin A in Mature Male Albino Rats. Sci.J. of Oct. 6 Univ.2(2), 175-179.

Copyright: (C) 2014 Magdy et al.. This is an open-access article distributed under the terms of the Creative Commons Attribution License, which permits unrestricted use, distribution, and reproduction in any medium, provided the original author and source are credited.

\title{
Immunosuppressive Toxic Effects of Ochratoxin A in Mature Male Albino Rats
}

\author{
*Magdy F. Abou El Fotoh ${ }^{1}$, Kamel M.A. ${ }^{2}$, Nora E. A. ${ }^{2}$ and Magda Hassan ${ }^{3}$ \\ ${ }^{1}$ Dept. of Forensic Med. and Toxicology, Faculty of Vet.Med., Zagazig University \\ ${ }^{2}$ Pharmacology Department and Physiology Department, Faculty of Vet.Med., Zagazig University \\ ${ }^{3}$ Veterinary Service Authority, Ministry of Agriculture
}

Received: 25-03-2014/ Revised: 16-04-2014 / Accepted: 20-04-2014

\begin{abstract}
Ochratoxin A (OTA) is a mycotoxin produced by species of the genus Aspergillus and penicillium. Human exposure has been demonstrated worldwide and its origin seems to be the intake of contaminated foods. Immunotoxic and genotoxic effects of OTA were investigated in mature male albino rats, when treated with garage in a close of 150,300 and 450 OTA $\mu \mathrm{g} / \mathrm{kg}$ B.wt. for 90 days. In the context several immune function assays were performed and bone marrow smears were obtained and stained in order to analyse micronuclei in polychromatic erythrocytes. The response of splenocytes to sheep red blood cells was decreased in a dose dependent manner. However, slightly statistically significant differences were obtained. Cytotoxic $\mathrm{T}$ lymphocytes activity was lower in the animals exposed to $150 \mathrm{OTA} \mu \mathrm{g} / \mathrm{kg} \mathrm{B}$.wt. but was not modified in the groups exposed to $300 \& 450 \mu \mathrm{g} / \mathrm{kg}$ B.wt.. The number of micronuclei in bone marrow polychromatic erythrocytes was slightly increased with respect to the control at any dose.
\end{abstract}

Key Words: Ochratoxin A, plenocytes, immunotoxic, genotoxic.

\section{Introduction}

Ochratoxin A (OTA) is a mycotoxin mainly produced by Aspergillus ochraceus, Aspergillus carbonarius and Penicillium verrucosum fungi species which may contaminate a variety of food, grains, meat and food stuffs ${ }^{(1)}$. Human exposure to OTA has been demonstrated in several European countries $^{(2)}$ as well as worldwide ${ }^{(3)}$. It has been proposed that OTA can be the etiologic agent of Balkan Endemic Nephropathy ${ }^{(4)}$. It may has also an immunotoxic, hepatotoxic, teratogenic, neur-otoxic and carcinogenic properties and has been classified by the IARC as a possible human carcinogen ${ }^{(5)}$. Due to its nephrotoxic properties, in 2010 in Africa, JECFA established a tolerable daily, intake of $10 \mathrm{ng} / \mathrm{kg}$ B.wt. which was reduced to $7.5 \mathrm{ng} / \mathrm{kg}$. b.wt. in $2010^{(6)}$ and to nill ng/kg B.wt. by Japan ${ }^{(7)}$. More recently, the EU scientific committee on food recommended the reduction of human exposure as such as possible, due to their concern regarding the potential genotoxicity of OTA and its mechanism of action as a carcinogen ${ }^{(8)}$. The OTA immunotoxic potential has been studied in different experimental models, after single and repeated administration of a wild range of doses given by various routes. Therefore, data available is often contradictory and difficult to interpret. OTA exposure affects the plasma levels of immunoglobulins in rats ${ }^{(9)}$. The antibody response to sheep red blood cells (SRBC) is suppressed in mice (10). Proliferative response of B cells is not modified by OTA in rats ${ }^{(9)}$ or mice ${ }^{(10)}$. OTA does not modify $\mathrm{T}$ cell response to mytogenic stimuli in rodents after 6,12 or 28 days ${ }^{(10)}$, but decrease is found after 90 days of exposure $^{(10)}$.

Data regarding OTA effects on NK cell activity is contradictory. A decrease of NK activity was observed in a study in mice (11). $\mathrm{T}$ cytotoxic lymphocyte (CTL) activity was not affected in mice ${ }^{(11)}$. In addition, OTA interferes with macrophage activity in mice ${ }^{(12)}$.

Although there is plentiful data as the toxic effect of OTA, very little has been published regarding the in-vivo exposure of this mycotoxin in mediumterm assays carried out in rats. With respect to immunotoxicity, it is not always evident from the studies whether the effects observed are truly immunotoxic or derived from acute toxic effects that exert an indirect inflow on immune system ${ }^{(9)}$. with respect to genotoxicity although it has been demonstrated that ingestion of OTA induces single-strand DNA breaks on rat livers and kidneys (13), and that increases the formation of DNA adducts in mice ${ }^{(14)}$. 
In vivo mutagenicity assays such as the micronuclei assay that detects clastogenic and/or aneugenic compounds, have not carried out.

Hence, it was the aim of this experiment to perform a 90 day general toxicity in rats in which several immuno functions assay could be carried out as well as enabling analysis of micronuclei in bone marrow polychromatic erythrocytes of the animals treated with the Ochratoxin A.

Test substances:

\section{Material and Methods}

Ochratoxin A (OTA) was kindly supplied from Mycotoxin Department, National Institute of Animal Health, Dokki, Cairo, Egypt. It was dissolved in $0.1 \mathrm{M} \mathrm{HNaCO}_{3} \mathrm{pH}$ 7.4. A sufficient amount of three different concentrations (150, 300 and $450 \mu \mathrm{g}$ OTA/ $\mathrm{kg} \mathrm{B.wt}$.) were used in vivo assay were prepared at $-150{ }^{\circ} \mathrm{C}$ until used.

\section{Experimental Design in vivo \\ Experimental animals:}

Eighty five mature male albino rats (body weight = $180 \pm 30 \mathrm{gm}$ ) were obtained from laboratory animal house, Faculty of Science, Zagazig University, Egypt. The rats housed in cages on a ventilated area, at a room temperature with a $12 \mathrm{~h}$ light/dark cycle. Rats were provided with food and water $a d$ libitum. The OTA feed level was lower than the tolerable daily intake were recommended with FAO/WHO, 2010.

\section{OTA animal treatment:}

The animals were distributed randomly into four group, the first group was control $(n=10)$ but 2 nd group $(\mathrm{n}=25)$ were received OTA $150 \mathrm{ng} / \mathrm{kg}$ b.wt., $3^{\text {rd }}$ group $(\mathrm{n}=25)$ were received $300 \mathrm{ng} / \mathrm{kg} \mathrm{b.wt.} \mathrm{and}$ the $4^{\text {th }}$ group $(\mathrm{n}=25)$ were received OTA $450 \mathrm{ng} / \mathrm{kg}$ b.wt. The treated animals by gavages with daily dosed for long 90 days. Control group was received $\mathrm{NaHCO}_{3}$.

\section{Isolation of immune cells:}

The animals were sacrified then the intraperitonial macrophages were isolated by infected $40 \mathrm{ml}$ of DMEM medium (Oxoid, Egypt) and harvesting after one minute. The spleens were removed aseptically, a cell suspension were prepared in RPMI 1640 medium, supplemented with fetal bovine serum (Biotech, Egypt), penicillin/ streptomycin (Epico Egypt), $50 \mu \mathrm{M}$ of 2- mercapto ethanol (Sigma, Egypt).

The cells were then washed in cold RPMI medium and re suspended in EMEM medium without phenol red (Sigma, Egypt). NK cells were isolated by gradient centrifugation technique ${ }^{(15)}$. NK cells were washed in MEME medium, counted in a hemocytometer and adjusted to $1 \times 10^{6}$ cells $/ \mathrm{m}$. lymphocyte were washed twice in RPMI 1640 medium, resounded in complete medium and then counted.

\section{Lymphocyte proliferation assay:}

The assay was performing following the protocols described in current proto in immunology ${ }^{(16)}$. Cells we seeded in round-bottom 96-well plates and the lymph proliferative agents were added to a final well concentration of $5 \mu \mathrm{g} / \mathrm{mL}$ concanavalin A and $20 \mu \mathrm{g} / \mathrm{mL}$ polysaccharide. After $72 \mathrm{~h}$ of incubation, the portion response was measured by the

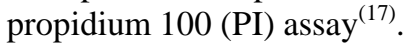

\section{Cytotoxic T lymphocyte (CTL) activity:}

Total CTL activity was measured without considering antigen specific $^{(18)}$. CTL precursors were cultured with mitogen agent cell (concanavolin A) during $72 \mathrm{~h}$ and then effect cells harvested and co cultured with cells for four hours. The percentage of lysed target cells was calculated by the propidium to assay ${ }^{(17)}$.

\section{Humoral response to sheep red blood cells (SRBC):}

Rat were immunized with SRBC (Bio Merieux, Egypt) suspension by intravenous administration $\left(2 \times 10^{8}\right.$ cells/ rat) four days before scarified spleen cells were isolated as previously described and antibody production was measured by the suspension hemolytic assay ${ }^{(19)}$.

\section{Micronucleus assay:}

The micronucleus test was performed ${ }^{(20)}$. Femurs were removed from the animals and a drop of bone marrow was placed on another drop of fetal calf serum on one and of a clean dry glass slide. Cells were spread with the aid of another slide and left to air-dry. Two slides were obtained per animal. They were stained with May-Gruen wald -Giemsa staining and after air- drying, they were mounted with DPXCP-xylene -bis (N-pyridium bromide). Slides were coded before microscopic examination. A total of 1000 polychromatic erythrocyte (PCEs) were analyzed per rat, and the frequently of micro nucleated polychromatic erythrocyte (MNPCEs) were also determined. The ratio of PCEs per normochromatic erythrocytes (NCEs) were calculated to determined the cytotoxic effects of OTA.

\section{Statistical analysis}

The statistical analysis is depended upon the significance of these preliminary tests of immune and genotoxic assay were analyzed by the one way analysis of variance (ANOVA) ${ }^{(21)}$. 


\section{Immune function assay:}

\section{Results}

The proliferative response of splenocytes affected by OTA exposure was shown in (Table 1). The CTL activity was lower in animals exposed to 150 $\mu \mathrm{g} / \mathrm{kg}$ b.wt. OTA but was not modified in the groups exposed to 300 and $450 \mu \mathrm{g}$ OTA/kg b.wt, (Table 2).

The response of splenocytes to SRBC was decreased in dose dependent manner; however the differences obtained were slightly significant (Table 2).

\section{Micronucleus assay:}

OTA induced slight significant increase in PCEs after 90 days of oral dosing with mycotoxin compared with control group $(\mathrm{P}=3.65)$. The results are presented in table (3). The frequency of $\mathrm{Mn}$ in NCEs was very low and slightly increases. PCS/ NCE ratio was greater than 1 at all of the concentration tested, in a range between 2.96 and 4.90 (Table 3).

\section{Discussion}

This study of toxic effects of OTA under different doses exposure regimen is extremely important in order to have more data for human assessment. Several studies on immunotoxic potential of OTA have been carried out, but seldom in the context of general toxicity testing. Therefore, the principal aim of this study was to obtain information about the immunotoxic properties of ochratoxin A, given orally to male white albino rats at different doses. Human data regarding plasma are generally less than $4 \mathrm{ng} / \mathrm{mL}$, with autlayers ranging up to $8-9$ $\mathrm{ng} / \mathrm{ml}$ with the exception of persons living in Balkan regions and middle East who have a higher level (50-100 nm/ml) (2).
In this study, the levels to which animals were exposed were above those of natural human exposure. The relatively high plasma concentrations of OTA at the end of the study can be explained by slow elimination of the toxin from the body.

Regarding the humoral response slight variation was observed in the proliferative response of splenocytes, slightly deviated from other studies (9\&10). The humoral response to SRBC decreased in a dose dependent manner, as previously observed (10 and 12). A decrease in the total CTL activity against target cells was observed in the group treated with $150 \mu \mathrm{g}$ OTA $/ \mathrm{kg} \mathrm{b}$.wt, but not in the other treated groups.

In this study, OTA has been administered for 90 days in the context of a general toxicity at 150, 300 and $450 \mu \mathrm{g} / \mathrm{kg}$ B.wt, as to determine immune function parameters at sub toxic OTA concentration for nephrotoxicity. Therefore, the animals have been exposed to OTA at much lower doses but during more days. In spite of the different regimen exposure, the possibility of obtaining more information from the study encouraged us to analyse $\mathrm{MN}$ in bone marrow erythrocytes, even if the doses tested were lower than those recommended.

The higher number of PCE found with respect to NCE resulted in a PCE/NCE ratio higher than 2 (range 2.96-4.90). This can be explained by the fact that approximately or $\mathrm{h}$ before the animals were sacrificed a substantial volume of blood was extracted from the retro-orbital sinus of the animals. This circum stance probably activated the erythropoietic process and consequently.

Conflict of Interest statement: The author declares no conflicts of interest.

Table (1): Effect of OTA on $\beta$ proliferative response to lipopolysaccharide, $T$ cell proliferative response to Canavalis A.

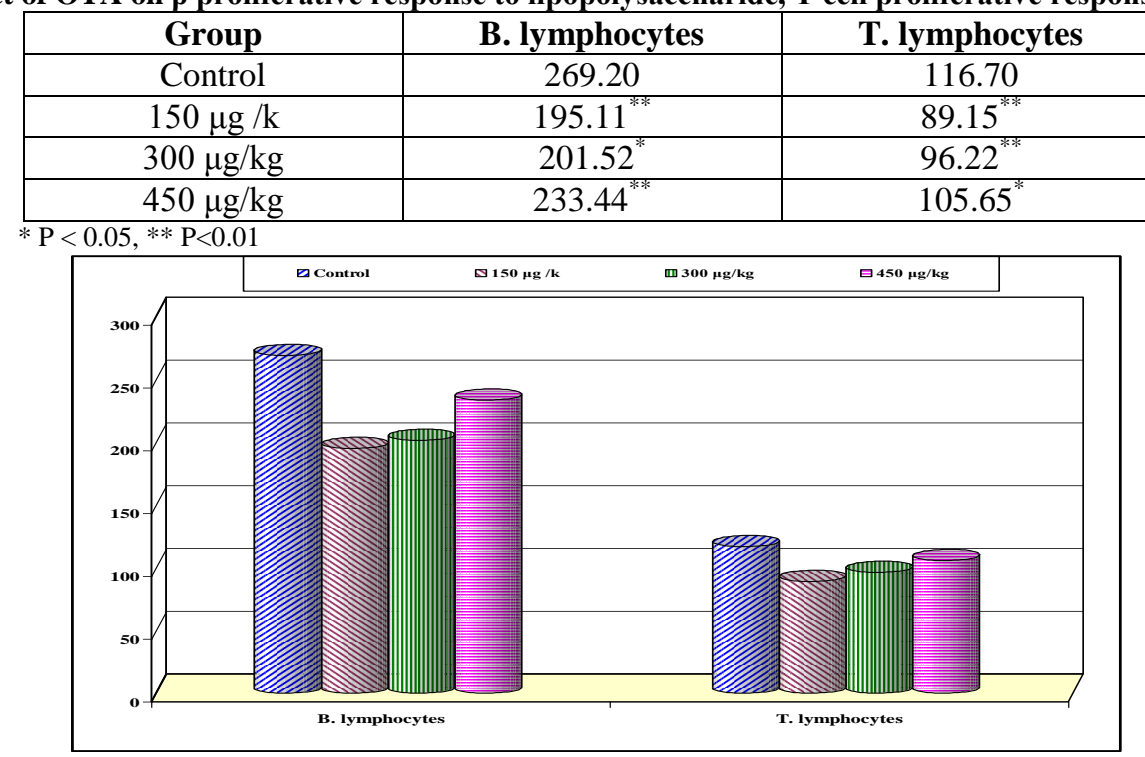

Fig. (1): Effect of OTA on $\beta$ proliferative response to lipopolysaccharide, T cell proliferative response to Canavalis A. 
Table (2): CTL cytotoxic activity and humoral response to SRBC after 90 days of treatment with OTA.

\begin{tabular}{|c|c|c|}
\hline Group & CTL activity & Hemolytic suspension assay \\
\hline Control & 14.75 & 1.28 \\
\hline $150 \mu \mathrm{g} / \mathrm{kg}$. OTA & $7.40^{* * *}$ & $0.92^{*}$ \\
\hline $300 \mu \mathrm{g} / \mathrm{kg}$ OTA & $17.05^{* * * *}$ & $0.88^{* * *}$ \\
\hline $450 \mu \mathrm{g} / \mathrm{kg}$ OTA & $15.65^{* *}$ & $0.79^{* * *}$ \\
\hline
\end{tabular}

$* \mathrm{P}<0.05, * * \mathrm{P}<0.01, * * * \mathrm{P}<0.001$

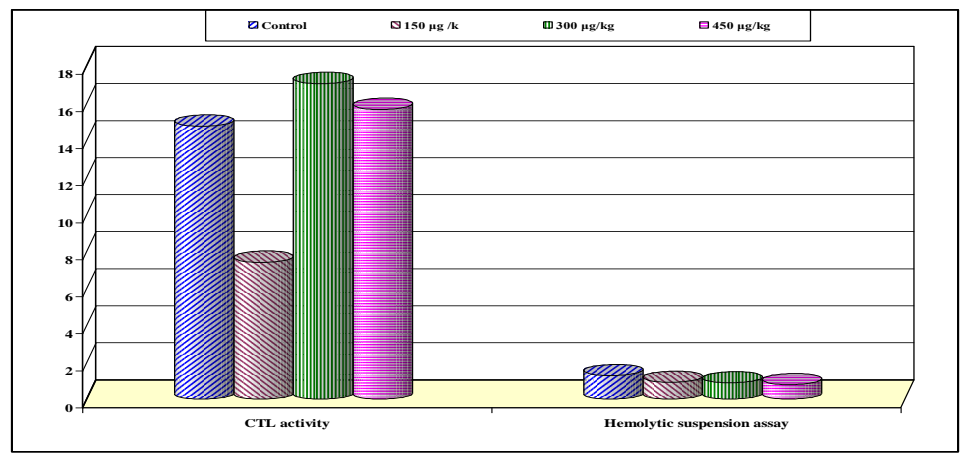

Fig. (2): CTL cytotoxic activity and humoral response to SRBC after 90 days of treatment with OTA.

Table (3): Micronucleus induction in mouse bone marrow cell of white albino rats after oral administration for 90 days.

\begin{tabular}{|c|c|c|c|c|}
\hline Group & PCE/NCE ${ }^{1}$ & $\mathrm{MN} / \mathbf{P C E}^{2}$ & $\mathrm{PCE} / \mathrm{n}^{3}$ & MN/NCE ${ }^{4}$ \\
\hline Control & $3.35+0.25$ & $3.22+0.25$ & $11.00 / 11$ & $0.35 \pm 0.60$ \\
\hline $150 \mu \mathrm{g} / \mathrm{kg} . \mathrm{OTA}$ & $4.90 \pm 0.21^{*}$ & $4.65 \pm 0.30^{*}$ & $11.00 / 11$ & $0.19 \pm 0.65^{* * x}$ \\
\hline $300 \mu \mathrm{g} / \mathrm{kg}$ OTA & $3.10 \pm 0.18^{*}$ & $5.85 \pm 0.19^{* *}$ & $8.00 / 8^{* * *}$ & $0.86 \pm 0.45^{* *}$ \\
\hline $450 \mu \mathrm{g} / \mathrm{kg}$ OTA & $2.96+0.13^{* 3}$ & $3.52+0.12$ & $11.00 / 11$ & $0.56 \pm 0.80$ \\
\hline
\end{tabular}

$* \mathrm{P}<0.05, * * \mathrm{P}<0.01, * * * \mathrm{P}<0.001$

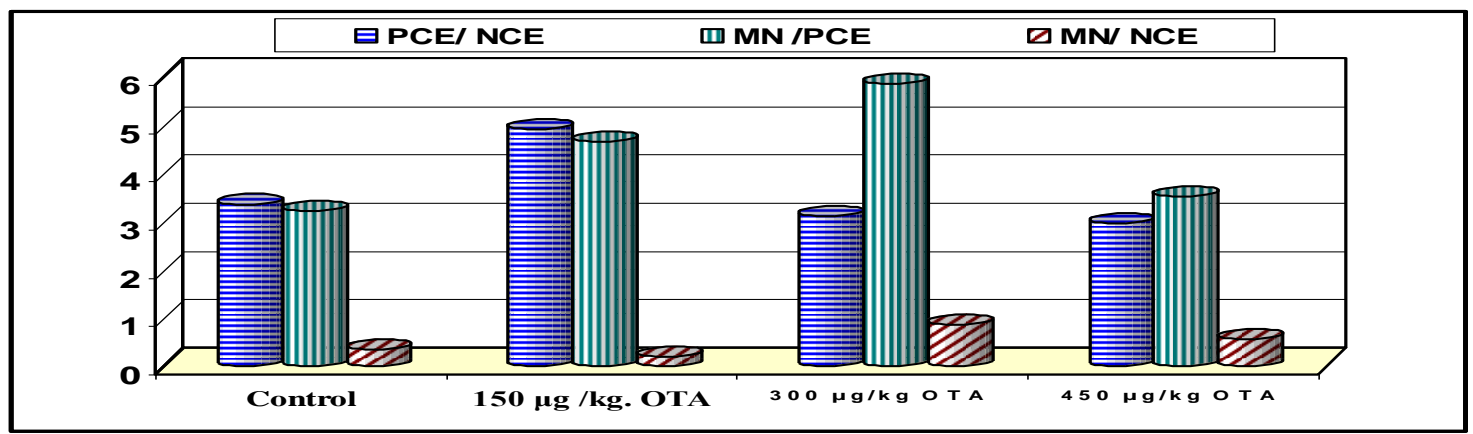

Fig. (3): Micronucleus induction in mouse bone marrow cell of white albino rats after oral administration for 90 days.

1- This ratio was calculated in a total of $1000 \mathrm{PCE}+\mathrm{NCE}$ examined/ animal.

2- MN was identified in a total of 1000 examined / animal.

3- Total number of PCE examined / number of animals.

4- MN were identified in a range of 125 -400 NCE which a total of 1000 erythrocytes examined.

\section{References}

1. Walker R. Risk assessment of ochratoxin A. Current views of the European scientific committee on food, the JECFA and the codex committee on food additives and contaminants. Advances in Experimental Medicine and Biology, 2002, 504, 249-225.

2. Lopez C. Ochratoxin A; exposure in Europe in comparison with a Middle East region. J. Toxicol. 2013, 19, 143-149.

3. Betbeder A and Creppy EE. Nutrition and human blood contamination by the Ochratoxin A in the western descerts. Appl. Toxicol. 2014, 1, 69-75.

4. Pfohl LA, Petkova BT, Chemozensky IN and Castegnaro M. Balkan endemic nephropathy and associated urinary tract tumors: A review on etiological causes and the potential role of mycotoxins. Food Additives and Contaminants, 2002, 19, 282-302.

5. IARC. The Evaluation of Teratogenic and Carcinogenic Risks of Chemicals to Humans; Some naturally occurring substances: Food items and constituents, heterocyclic aromatic and mycotoxins. International Agency for Research on Cancer, 2013, 365, 586-609.

6. FAO/WHO. Evaluation of certain food additives and contaminants, 2010. WHO Technical Report Series, 2010, $908,146-150$ 
7. FAO/WHO. Evaluation of certain food additives and contaminants, 2013. WHO Technical Report Series, 2003, 1002, 33-39.

8. European Commission (1998). Opinion of the scientific committee on food on Ochratoxin. Anex II document XXIV/2210/ 98

9. Dortant PM, Peters GWM, Van Loveren H, Marquardt RR and Speij GJA. Age related differences in the toxicity of ochratoxin A in female rats. Food and Chemical Toxicology, 2001, 39, 55-65.

10. Thuvander A, Breitholtz A. and Olsen M. Effects of Ochratoxin A on the mouse immune system after sub chronic exposure. Food and Chemical Toxicology, 1995, 33, 1005-1011.

11. Luster MI, Gemolec DR, Burleson Q, Jameson CW, Ackerman MF. and Kenneth R. Selective immunosupression in mice of natural killer cell activity by Ochratoxin A. Cancer Research , 1987, 47, 2259-2263.

12. Muller GG, Kielstein H, Brendt A and Rosner H. Studies of the influence of Ochratoxin $\mathrm{A}$ on immune and defense reactions in the mouse model. Mycoses, 1995, 38:85-91.

13. Kane A, Creppy EE, Roth A, Roschenthaler $\mathrm{R}$ and Dirhaimer G. Distribution of the $\left[{ }^{3} \mathrm{H}\right]$-label from low doses of radioactive Ochratoxin A ingested by rats, and evidence for DNA-single strand breaks caused in liver and kidneys. Archives of Toxicology, 1986, 58, 219-224.

14. Pfohl-Leszkowiez A, Grosse Y, Kane A, Gharbi A, Baudrimont I, Obrecht S, Creppy EE and Dirheimer G. Is the oxidative pathway implicated in genotoxicity of Ochratoxin A? Furotext Ltd, 1993, 33, 177-187.

15. Patel MR and Lima TJ. Enrichment of mouse splenic natural killer cells using discontinuous polyvinyl pyrrolidone silica (percall) gradients. Immunology, 1984, 53, 721-729.

16. Coligen JE, Kruisbeek AM, Margulies DH, Shevach EM and Strober W. (1991). Current protocols in Immunology, New York, Green Publishing and Weley Interscience.

17. Vollenweider I. and Groscurth P. Comparison of four DNA staining fluorescence dyes for measuring cell proliferation of lymphokine activated killer (LAK) cell. J. Immunological Methods, 1992, 149,133-135.

18. Muchmore AE, Nelson DL, Kirschner H and Blaese RM. A reappraisal of the effector cells mediating mitogen induced cellular cytotoxicity. Cellular Immunology, 1975, 19, 78-90.

19. Han SlB, Oh GT, Yun YP, Min MK, Hyun BH and Kim HM. Rapid determination of in vivo and in vitro antibody responded by suspension hemolytic assay. J. Pharmacological and Toxicological Methods, 1996, 36, 33-40.

20. Adler ID. Cytogenetic tests in mammals. Mutagenicity Testing: A practical Approach. IRL Press, Oxford, 1994, 298-302.

21. SAS (1999). Users Guide, Virgin 8. SAS Institute Inc., Cary, NC, USA. 